\title{
Collie Eye Anomaly in Australian Kelpie dogs in Poland
}

\author{
Natalia Kucharczyk ${ }^{1}$, Anna Cislo-Pakuluk ${ }^{1}$ and Peter Bedford ${ }^{2 *}$ (B)
}

\begin{abstract}
Background: To report the occurrence of choroidal hypoplasia in the Australian Kelpie breed in Poland, the affected dogs testing positive for the Collie Eye Anomaly NHEJ1 gene mutation.

Case presentations: Choroidal hypoplasia $(\mathrm{CH})$ was initially diagnosed in a young female Australian Kelpie presented for routine ophthalmological examination prior to breeding. Indirect ophthalmoscopy revealed tigroid fundi bilaterally with areas of abnormally arranged choroidal vasculature temporal to the optic disc. These lesions had the appearance of the choroidal hypoplasia diagnostic for Collie Eye Anomaly, a genetically determined disease seen most commonly in Collie types.

The DNA based test for the NHEJ1 gene mutation that is confirmatory for Collie Eye Anomaly proved the dog to be homozygous for this mutation. Twenty one other related dogs were subsequently examined genetically, the dam proving to be affected and eight others were shown to be carriers.

Conclusions: This report demonstrates that Collie Eye Anomaly is present in a Polish bred Australian Kelpie line and as such breeders in this country and those importing dogs or semen internationally should be aware of other possible cases.
\end{abstract}

Keywords: Australian Kelpie, Choroidal hypoplasia, Collie Eye Anomaly, NHEJ1 gene

\section{Background}

Collie Eye Anomaly (CEA) is a congenital canine pleomorphic ocular disease characterized by two main lesions, choroidal hypoplasia/chorioretinal dysplasia (CH/CRD) and papillary/peripapillary colobomata. $\mathrm{CH} / \mathrm{CRD}$, referred to as $\mathrm{CH}$ in this paper, is characterized by the focal absence of pigmented choroidal tissue and tapetum temporal to the optic disc and the presence of choroidal blood vessels abnormal in both appearance and arrangement. If the lesion also involves part of the non-tapetal fundus the overlying retinal pigment epithelium lacks pigment. $\mathrm{CH}$ is always bilaterally present, but to varying degrees between affected dogs and even within the same individual. However, no matter how extensive, $\mathrm{CH}$ appears to be of no clinical significance in terms of an effect on sight. Colobomatous defects can vary considerably in size, the larger lesions affecting vision and potentially being involved in post-natal retinal detachment. In addition to these two features both congenital and post-natal retinal detachment

\footnotetext{
* Correspondence: profg1@btinternet.com

${ }^{2}$ Royal Veterinary College, London, UK

Full list of author information is available at the end of the article
}

and intraocular haemorrhage are also described, but although potentially blinding, these features are of low incidence [1-5]. Thus CEA affected dogs can vary from mildly to moderately affected without vision impairment or possibly present with partial or total blindness.

A number of studies concerning the genetic background of the disease have been completed [6-12], one initial suggestion being that CEA might be inherited as a complex trait involving multiple genetic factors [5]. Subsequently it has been shown to be an autosomal recessive trait in Collie types and Lowe et al. localized a 3.9 - cM locus associated with $\mathrm{CH}$ on chromosome 37 [9]. Fine mapping techniques have been used to identify a $7.8 \mathrm{~kb}$ deletion in intron 4 of the NHEJ1 gene(non-homologous end-joining factor 1), the CEA locus [10]. $\mathrm{CH}$ has been shown to be due to the same NHEJ1 deletion in several other breeds and a confirmatory genetic test is now commercially available.

CEA was first described as an hereditary disorder in the Border Collie, Rough and Smooth Collies and the Shetland Sheepdog $[1-5,13,14]$. It has also been variously reported in several other breeds including the 
Australian Shepherd, the Boykin Spaniel, the Lancashire Heeler, the Longhaired Whippet, the Nova Scotia Duck Tolling Retriever, the Hokkaido dog and the Silken Windhound [15-20]. A phenotypically identical lesion has been seen in other non-collie breeds including the German Shepherd Dog, Miniature and Toy Poodles, the Beagle and a mixed-breed dog $[17,18,20]$. The causal genetic defect has not been determined for all of these breeds.

This is the first published report of CEA in the Australian Kelpie breed. The initial ophthalmoscopic finding was subsequently confirmed using the specific DNA based test. Based on analysis of the probands' pedigree the dog's dam proved to be homozygous for the mutation and one other affected dog plus several carriers were found.

\section{Case presentation}

The initial finding was in a two-and-a-half year old female Australian Kelpie which was being considered for breeding purposes. There were no reported visual deficits and performance in a maze test, the menace response, the pupillary light reflexes and the dazzle reflex were all considered to be normal. Biomicroscopic examination (SL-17 Portable Slit Lamp, Kowa) of the anterior segment revealed minor bilateral stromal iridal atrophy. Mydriasis was effected using tropicamide (Tropicamidum WZF 1\%, Polfa Warszawa) and fundus examination completed using direct and indirect ophthalmoscopy (Keeler Standard Direct and Keeler Vantage Plus Indirect ophthalmoscopes). Fundus imaging was obtained using a 30D condensing lens (Volk 2) and photographs were taken using the ClearView Fundus Camera (Optibrand). Both fundi had a tigroid appearance in the non-tapetal areas, but an irregular arrangement of the choroidal vasculature was observed bilaterally in the temporal region of the tapetal fundus. The lesions were easily identifiable with the choroidal blood vessels being fewer in number and thicker than normal. The degree of $\mathrm{CH}$ allowed the white appearance of the sclera to be visible between the abnormal blood vessels (Fig. 1a-c). Colobomatous lesions were not present and no other ocular abnormalities were found. Based on the presence of $\mathrm{CH}$ a tentative diagnosis of CEA was suggested, this diagnosis being subsequently confirmed using a real time PCR DNA test for the CEA NHEJ1 $7.8 \mathrm{~kb}$ deletion gene mutation (Laboklin $\mathrm{GmbH}$ \& Co.KG, 8304).

Using an analysis of the probands' pedigree twenty other dogs related to the affected female were subsequently screened using the DNA test for the CEA mutation. Five of these dogs were also examined clinically and $\mathrm{CH}$ lesions were found in one, the dog's dam. Here the small size of lesions rendered a positive ophthalmoscopic diagnosis difficult (Fig. 2), demonstrating the value of litter screening
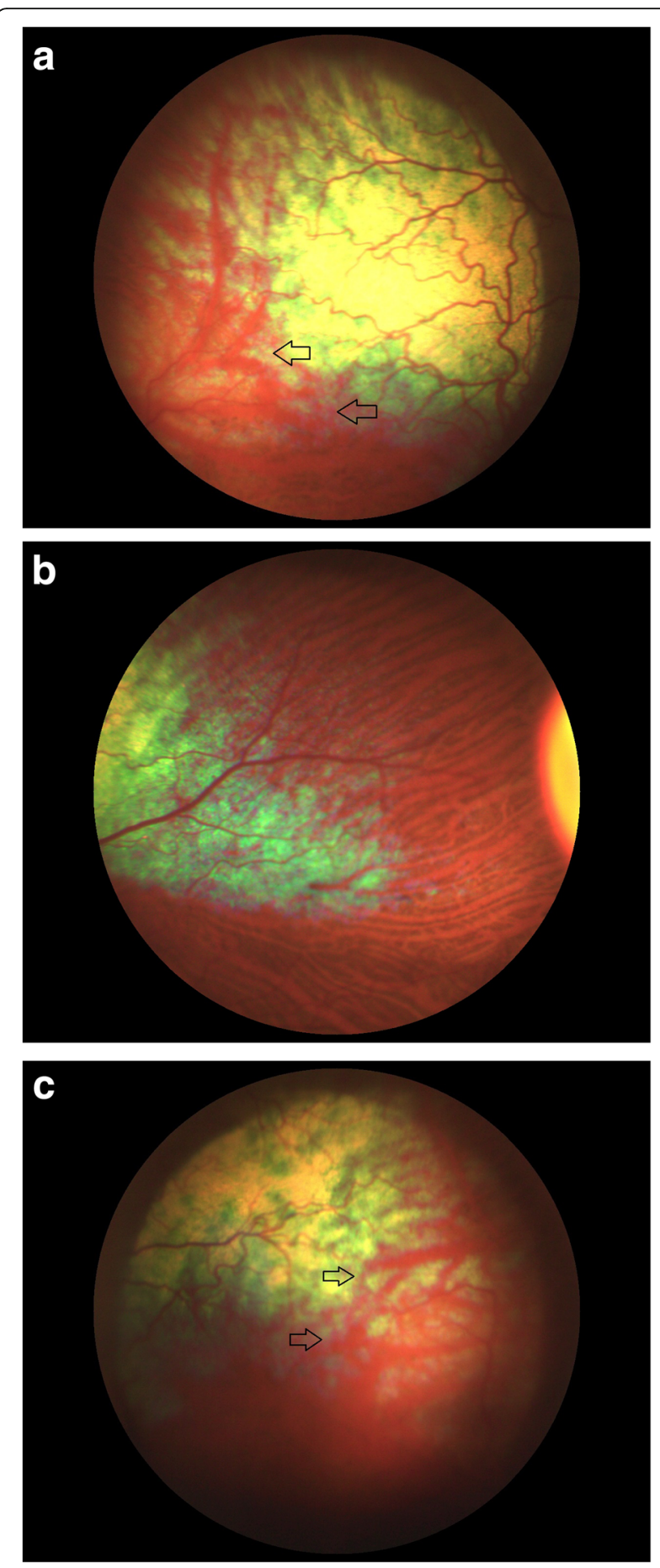

Fig. 1 Fundus photographs of the affected female to demonstrate the abnormal arrangement of choroidal vessels in the temporal tapetal fundus. a Left eye, temporal area, the arrowsdemonstrating the large area of choroidal hypoplasia. b Right eye, medial area, demonstrating a normal appearance. c Left eye, temporal area, demonstrating choroidal hypoplasia 


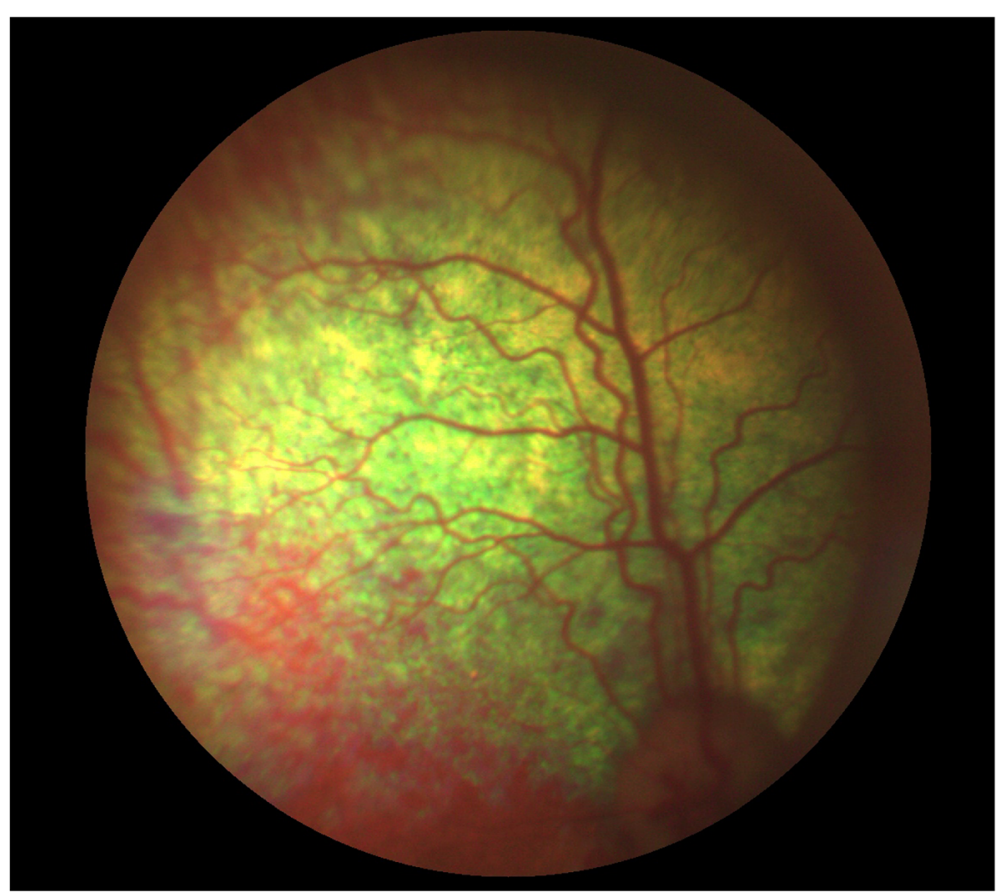

Fig. 2 The temporal area of the right fundus of the affected dam demonstrating a small area of choroidal hypoplasia

at six to 8 weeks of age to rule out a putative "go normal" diagnosis. However DNA testing confirmed the CEA diagnosis for this dog whilst eight others were shown to be carriers for the disease (Fig. 3). Colobomatous lesions and other possible features of CEA were not found in any of these dogs.

Permission has been obtained from all the owners and breeders whose dogs were involved in this study to record and publish both the clinical findings and the DNA results.

\section{Discussion and conclusions}

This is the first report of CEA in the Australian Kelpie breed, diagnosed on the basis of bilateral $\mathrm{CH}$ seen ophthalmoscopically and confirmed by genetic testing. The breed originated from British dogs imported into Australia for stock work in the early nineteenth century. They were simply described as collies or colleys, before the more traditional "collie" breeds were established. This background indicated that CEA could be present in the Kelpie and was the reason for this small study. $\mathrm{CH}$ lesions and the association with the CEA related NHEJ1 mutation could be reported,but colobomatous defects and the other features of CEA were not seen in either of the affected dogs. Further screening is required to evaluate the prevalence of the NEHJ1 gene mutation in this breed and breeders should be aware that in addition to the use of the DNA test and the ophthalmoscopic examination of the breeding stock, litter screening at six to 8 weeks of age will identify both $\mathrm{CH}$ and possible colobomatous lesions. The existence of a "go normal" change in which $\mathrm{CH}$ lesions can be masked by pigmentation beyond 12 weeks of age means that in adult dogs ophthalmoscopic examination needs to be supported by DNA testing to effect efficient disease control.

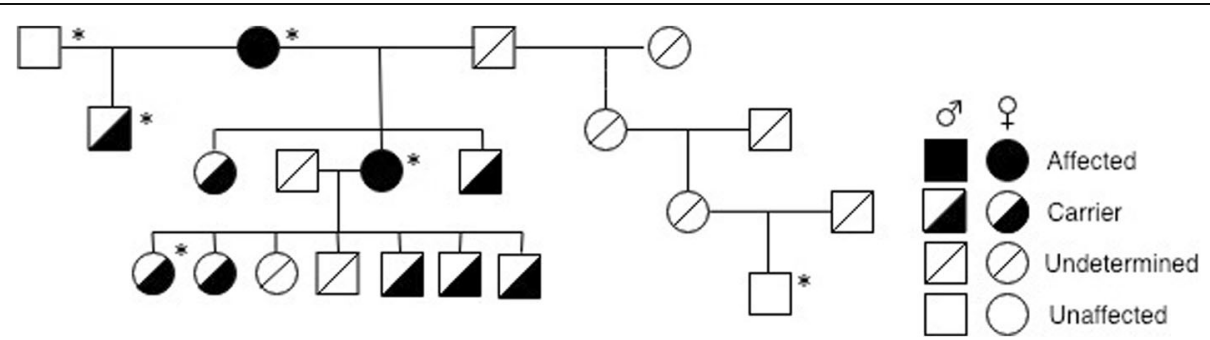

Fig. 3 Pedigree analysis of the 21 related Australian Kelpie dogs examined on the survey. The subject of this case report is the affected dog on the second line and asterisks mark the six dogs clinically examined 


\section{Abbreviations}

CEA: Collie Eye Anomaly; $\mathrm{CH}$ : Choroidal hypoplasia, focal absence of choroidal tissue temporal to the optic disc; CRD: Chorioretinal dysplasia; DNA: Deoxyribonucleic acid; NHEJ1: Non-homologous end-joining factor 1

\section{Acknowledgements}

The authors acknowledge the held of the several breeders who volunteered their dogs for the study.

\section{Authors' contributions}

All three authors were equally involved in the clinical assessment of the dogs (NK, AC-P and PB), the manuscript preparation (NK, AC-P and PB) and all have read and approved the final manuscript (NK AC-P and PB).

\section{Funding}

There were no funding issues as all costs were met by the breeders.

\section{Availability of data and materials}

The datasets used during the current study are available from the corresponding author on reasonable request.

\section{Ethics approval and consent to participate}

There were no associated ethical issues in this clinical study and all the dog breeders involved gave written consent for their participation, seeing the study as vital to future breeding programmes and the wellbeing of the breed.

\section{Consent for publication}

The authors would like to thank the breeders of all the dogs included in this clinical study for their participation and their permission to publish the results. Written consent in both Polish and English to publish all the personal and clinical details together with the identifying images and the pedigree analysis has been obtained and the statements are available for scrutiny. These records are held by both the authors and the breeders.

\section{Competing interests}

The authors declare that they have no competing interests.

\section{Author details}

${ }^{1}$ Viva Veterinary Clinic, Wroclaw, Poland. ${ }^{2}$ Royal Veterinary College, London, UK.

Received: 23 April 2019 Accepted: 14 October 2019

Published online: 04 November 2019

\section{References}

1. Donovan EF, Wyman M. Ocular fundus anomaly in the collie. J Am Vet Med Assoc. 1965;147(12):1465-9.

2. Roberts SR. The collie eye anomaly. J Am Vet Med Assoc. 1969;155(6):859-65.

3. Wyman M, Donovan EF. Eye anomaly of the collie. J Am Vet Med Assoc. 1969;155(6):866-70.

4. Donovan $\mathrm{RH}$, Freeman HM, Schepens CL. Anomaly of the collie eye. J Am Vet Med Assoc. 1969;155(6):872-7.

5. Bedford PGC. Collie eye anomaly in the United Kingdom. Vet Rec. 1982; 111(12):263-7

6. Yakely WL, Wyman M, Donovan EF, Fechheimer NS. Genetic transmission of an ocular fundus anomaly in Collies. J Am Vet Med Assoc. 1968;152(5):457-61.0.

7. Yakely WL. Collie eye anomaly: decreased prevalence through selective breeding. J Am Vet Med Assoc. 1972;161(10):1103-7.

8. Wallin-Håkanson B, Wallin-Håkanson N, Hedhammar A. Influence of selective breeding on the prevalence of chorioretinal dysplasia and coloboma in the rough collie in Sweden. J Small Anim Pract. 2000;41(2):56-9.

9. Wallin-Håkanson B, Wallin-Håkanson N, Hedhammar A. Collie eye anomaly in the rough collie in Sweden: genetic transmission and influence on offspring vitality. J Small Anim Pract. 2000;41(6):254-8.

10. Lowe JK, Kukekova AV, Kirkness EF, Langlois MC, Aguirre GD, Acland GM, et al. Linkage mapping of the primary disease locus for collie eye anomaly. Genomics. 2003 Jul;82(1):86-95

11. Parker HG, Kukekova AV, Akey DT, Goldstein O, Kirkness EF, Baysac KC, et al. Breed relationships facilitate fine-mapping studies: a 7.8-kb deletion cosegregates with Collie eye anomaly across multiple dog breeds. Genome Res. 2007;17(11):1562-71.

12. Chang H-S, Mizukami K, Yabuki A, Hossain MA, Rahman MM, Uddin MM et al. A novel rapid genotyping technique for Collie eye anomaly: SYBR Green-based real-time polymerase chain reaction method applicable to blood and saliva specimens on Flinders Technology Associates filter paper. J Vet Diagn Invest. 2010;22(5):708-15.

13. Barnet KC, Stades FC. Collie Eye Anomaly in the Shetland Sheepdog in the Netherlands. J Small Anim Pract. 1979:20(6):321-9.

14. Bedford PGC. Collie Eye Anomaly in the Border Collie. Vet Rec. 1982;111(2):34-5.

15. Rubin L, Nelson B, Sharp C. Collie eye anomaly in Australian Shepherd dogs. Prog Vet Comp Ophthalmol. 1991;1:105-8.

16. Bedford PG. Collie eye anomaly in the Lancashire heeler. Vet Rec. 1998; 143(13):354-6.

17. Rampazzo A, D'Angelo A, Capucchio MT, Sereno S, Peruccio C. Collie eye anomaly in a mixed-breed dog. Vet Ophthalmol. 2005;8(5):357-60.

18. Mizukami K, Chang H-S, Ota M, Yabuki A, Hossain MA, Rahman MM, et al. Collie eye anomaly in Hokkaido dogs: case study. Vet Ophthalmol. 2012; 15(2):128-32.

19. Brown EA, Thomasy SM, Murphy CJ, Bannasch DL. Genetic analysis of optic nerve head coloboma in the Nova Scotia Duck Tolling Retriever identifies discordance with the NHEJ1 intronic deletion (collie eye anomaly mutation). Vet Ophthalmol. 2018;21(2):144-50.

20. Priester WA. Congenital ocular defects in cattle, horses, cats and dogs. J Am Vet Med Assoc. 1972;160(11):1504-11.

\section{Publisher's Note}

Springer Nature remains neutral with regard to jurisdictional claims in published maps and institutional affiliations.
Ready to submit your research? Choose BMC and benefit from:

- fast, convenient online submission

- thorough peer review by experienced researchers in your field

- rapid publication on acceptance

- support for research data, including large and complex data types

- gold Open Access which fosters wider collaboration and increased citations

- maximum visibility for your research: over $100 \mathrm{M}$ website views per year

At BMC, research is always in progress.

Learn more biomedcentral.com/submissions 